\title{
What impedes micro, small and medium firms' growth the most in South Africa? Evidence from World Bank Enterprise Surveys
}

\author{
A.M. Mthimkhulu and M.J. Aziakpono* \\ University of Stellenbosch Business School, P.O. Box 610, Bellville 7535, South Africa \\ *To whom all correspondence should be addressed \\ meshach.aziakpono@usb.ac.za
}

\begin{abstract}
The growth of Micro, Small and Medium Enterprises (MSMEs) is often regarded as a solution to persistent unemployment in developing countries. Studies have shown that access to finance is the most serious obstacle to MSMEs' growth. This paper investigates key obstacles to the growth of MSMEs in South Africa using the World Bank Enterprise Surveys of 2003 and 2007. Two approaches are used to determine the key obstacles. The first improves on the simple count-of-ratings method used by many researchers. The second estimates the effects of obstacles on growth through sequential multivariate regressions based on the Growth Diagnostics framework by Hausmann, Rodrik \& Velasco (2005) and identifies two levels of obstacles' intensities: binding constraints with negative and significant effects and constraints with notable effects whose negative effects are significant but less than the binding. From both count- and regression-based analyses, access to finance is a relatively less important obstacle. The count-based analysis finds crime to be the top obstacle. In the regressions, 'courts', which refers to the efficacy of the legal system and thus related to crime, is binding. Electricity and transportation of goods are the constraints with notable effects.
\end{abstract}

\section{Introduction}

The World Development Report of 2013 (WDR, 2013) emphasises the role of the private sector in social and economic development. It submits that the availability of jobs, especially from the private sector, boosts living standards, raises productivity, and fosters social cohesion and contends that formal employment is "the principal way out of poverty" (WDR, 2013: 58). On average, 70 percent of jobs in developing countries are accounted for by MSMEs, making them an important part of the private sector. WDR (2013) further reveals that sub-Saharan Africa requires an annual job creation rate of 2.7 percent (the largest of all regions) to maintain an already worrisome employment to working-age ratio which has at least 40 percent of the employable population without jobs. It is thus imperative that obstacles to MSMEs' growth be carefully studied in Africa. This paper is a modest contribution in that regard. Focusing on South Africa, the paper identifies, ranks and determines the most important obstacles to the job creation capacity of MSMEs.

The paper builds on the Growth Diagnostics framework of Hausmann et al. (2005) and uses the World Bank Enterprise Surveys of South Africa of 2003 and 2007. Growth Diagnostics is based on the premise that not all obstacles to growth are equally binding and that by determining and eliminating the most binding, optimal growth is realised even though other obstacles are still in place. In enterprise development research, the World Bank Enterprise Surveys data have been used to identify top and binding constraints. This is because the Enterprise Surveys have summarised the extensive list of obstacles in the literature to 15 , making the data a reasonable starting point for investigating key constraints. In the Enterprise Surveys, firms report on whether each of the 15 obstacles is 'not an obstacle', a 'minor', 'moderate', 'major' or a 'very severe obstacle' to their operations. Obstacles include employees' skills adequacy, access to finance, electricity, crime and efficiency of the legal system amongst others.

From the list, a pertinent question to ask is which obstacles, or better still which obstacle, must be prioritised given limited resources and the impracticality of tackling all at once? Ayyagari, Demirguc-Kunt \& Maksimovic (2008), Dihn, Mavridis \& Nguyen (2010), and to a lesser extent Beck, Demirguc-Kunt \& Maksimovic (2005), address the question and base their investigations on the Growth Diagnostics framework. Beck et al. (2005) use World Business Environment Surveys of 1999 to 2000 to investigate if the effects of access to finance, legal obstacles and corruption on growth are determined by firm size. They find that firms employing 5 to 50 workers are significantly affected by the three constraints.

Ayyagari et al. (2008) also use World Business Environment Surveys. Unlike Beck et al. (2005), who begin their analysis with an a priori list of three obstacles, Ayyagari et al. (2008) use an artificial intelligence-based Directed Acyclic Graph (DAG) methodology to determine three obstacles affecting growth the most. They find access to finance, crime and political instability to be the top obstacles. The authors then determine the most binding using multivariate regression analysis. The top three obstacles enter the regression all at once along with firm and country variables as control. Finance is found to have the largest effect on growth and thus deemed binding. 
Dihn et al. (2010) use the Enterprise Surveys of 2007 to 2010 , to identify top constraints by a count of responses of firms' ratings of obstacles and find electricity, finance and tax rates as top obstacles. They determine the binding constraint through three sets of sequential regressions. The first set examines the independent effect of an obstacle on growth. In the second set, all obstacles enter the regression at once for each obstacle's effects in the presence of other obstacles to be determined. In the final set, only obstacles significant in the second enter the regression. All regressions have intercept term, firm and country characteristics as control variables. Finance emerges as most binding.

The foregoing three studies are cross-country. The first has 54 countries from the developed and developing world, the second 80 from the same, while the third has 96 developing countries. Although all find finance binding, the top constraints vary. Two datasets from different periods made up of different countries can indeed be reasonably expected to yield different top constraints. But importantly, the difference suggests the distinctiveness of countries. Gelb, Ramachandran, Shah \& Turner (2007) explore how obstacles vary in 27 African countries (including South Africa) using Enterprise Surveys. They determine the top obstacles for each country in two ways: firstly by a count of firms' own subjective ratings of the obstacles, which the authors find differ considerably from country to country. Secondly, they estimate the effects of the obstacles using more objective indicators on growth, for example in the case of electricity, by substituting the rating of electricity with the actual number of power supply interruptions. They find that the effects of the objective measures of obstacles on growth vary with countries' levels of per capita income.

It may seem trivial to emphasise that obstacles differ by country. Yet, in the context of the cross-country enterprise development literature, to so emphasise is necessary due to the fact that the peculiarities of countries are smoothed-off in cross country studies such that resultant policy diagnoses are generic best suiting the average country. Country-specific studies become necessary to identify specific issues that can credibly inform policy. This paper demonstrates that policy recommendations drawn from a country-specific study can vary considerably from cross-country extrapolations. For instance, whereas studies of MSMEs in developing countries find access to finance as the top and binding constraint, this study finds the top constraint for all firms in South Africa to be crime, and the most binding for MSMEs to be the efficacy of the legal system i.e. courts. After grouping firms by size, age, sector, location and owner's gender and ethnic origin it is clear that the intensity of constraints is not consistent but varies across the groups. Medium-sized enterprises are mildly affected by all obstacles reviewed, while small firms are collectively constrained by 'courts' and electricity. The study finds limited effects of obstacles on firms in Durban and Port Elizabeth ${ }^{1}$. Access to finance is only a significant constraint

${ }^{1}$ The World Bank Enterprise Surveys were conducted in four cities: Cape Town, Durban, Johannesburg and Port Elizabeth. Because the Durban and for small European-owned ${ }^{2}$ firms and small firms in Cape Town. The results affirm the view that a study of local circumstances identifies key obstacles with greater precision and engenders robust policy recommendations.

\section{MSME sector in South Africa}

Unemployment has been a perennial problem in South Africa. The enterprise development policy framed in 1995 regards MSMEs as key to creating jobs and integrating the post-apartheid society (SA National Strategy, 1995). The Black Economic Empowerment (BEE) legislation post-2003 has been an important strategy to implement the policy. The BEE legislation has a score card system with a total of 105 points. Established organisations are to earn the points by spending at least 3 percent of their annual net profit after tax on the score card's five elements. Of the five, two are closely associated with MSMEs: firstly, enterprise and supplier development with 40 points and socioeconomic development with 5 points. In essence, the BEE legislation has obliged all established entities to facilitate the growth of MSMEs. In most economies such expenditures would be voluntary corporate social investment. Given that it is otherwise in South Africa, it becomes quite important to identify key obstacles to growth and approximate the effects of such obstacles on growth so that the broad-based support from public, private and social economy actors can be informedly channelled.

In investigating the key obstacles, researchers often present a list of possible obstacles for entrepreneurs to rate. A simple count of responses determines the top constraints. Dihn et al. (2010), Gelb et al. (2007) and Ayyagari, Beck \& Demirguc-Kunt (2003) adopt this approach on Enterprise Survey data. The problem with the approach is that the firms will only be responding to a specific obstacle and rating only that obstacle but not ranking the obstacle against 14 others. To address this weakness within the World Bank Enterprise Survey instrument, this paper uses responses to the question "among the issues numbered 1 to 15 , please indicate which one constitutes: the most serious obstacle; the second most serious obstacle; the third most serious obstacle". A score of 3 is assigned to the first most serious constraint, 2 to the second and 1 to the third most serious. Multiplying the score by the observed frequencies and summing the product of the first, second and third most serious obstacle for each firm, the relative importance of each of the 15 obstacles is determined by ranking the obstacles. The results for all firms are graphed in Figure 1 against results from a simple count of ratings above a 'moderate' rating. In both, crime is the top obstacle followed by electricity. Access to finance is the fourth on the simple count method but fifth in the alternative approach, while worker education becomes the fourth most important from being seventh in the simple count approach.

Port Elizabeth samples are smaller we combined the two under 'Durban and Port Elizabeth'.

${ }^{2}$ The World Bank Enterprise Surveys in South Africa list six ethnic groups for business owners: African, European, Indian, Lebanese or Middle Eastern, Other Asian and Other. We aggregate the last five under 'Asian'. 


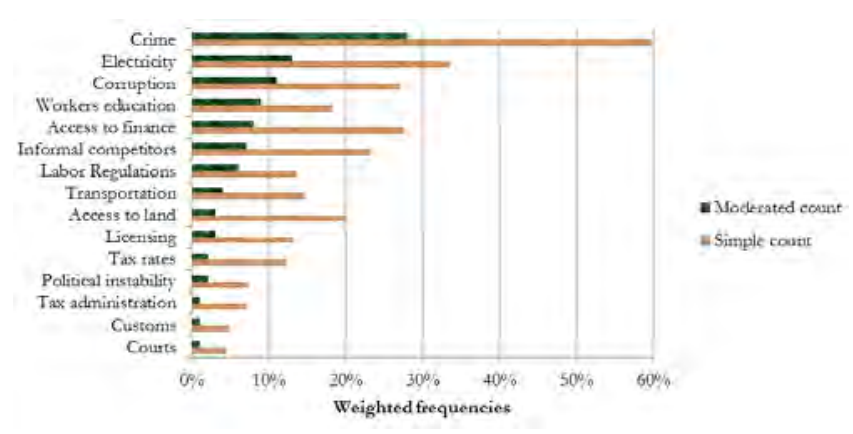

Figure 1: Rating of constraints by firms in South Africa

Source: Authors' estimations based on World Bank Enterprise Surveys of South Africa (2007)

Table 1 reports the top 5 obstacles by firm size. Crime is the top obstacle across all firm sizes. Access to finance only appears as a second top obstacle for micro enterprises.

Table 1: Relative weights (\%) of top 5 obstacles faced by MSMEs in South Africa

\begin{tabular}{|c|c|c|c|c|c|}
\hline \multicolumn{2}{|c|}{ Constraint } & \multicolumn{4}{|c|}{ Size of enterprise } \\
\hline Rank & $\begin{array}{l}\text { Name of } \\
\text { constraint }\end{array}$ & Micro & Small & Medium & $\begin{array}{l}\text { MSME } \\
\text { s }\end{array}$ \\
\hline 1 & Crime & 17.61 & 29.90 & 30.91 & 28.49 \\
\hline 2 & Electricity & 9.58 & 13.75 & 11.69 & 12.25 \\
\hline 3 & Corruption & & 10.36 & 11.74 & 10.45 \\
\hline 4 & $\begin{array}{l}\text { Access to } \\
\text { finance }\end{array}$ & 14.93 & 10.11 & & 9.44 \\
\hline 5 & $\begin{array}{l}\text { Practices of } \\
\text { competitors in } \\
\text { the informal } \\
\text { sector }\end{array}$ & 10.70 & 9.57 & & 7.81 \\
\hline- & $\begin{array}{l}\text { Inadequate } \\
\text { education }\end{array}$ & & & 11.05 & \\
\hline- & $\begin{array}{l}\text { Labour } \\
\text { regulations }\end{array}$ & & & 7.38 & \\
\hline \multirow[t]{2}{*}{-} & Transportation & 10.00 & & & \\
\hline & $\begin{array}{l}\text { Total weight } \\
\text { of the } 5 \text { key } \\
\text { constraints }\end{array}$ & 62.82 & 73.69 & 72.76 & 68.44 \\
\hline
\end{tabular}

Source: Authors' estimations based on World Bank Enterprise Surveys of South Africa (2007)

Figure 2 compares some of the top obstacles in South Africa reported in Figure 1 to the top obstacles of the 96 developing economies in Dihn et al. (2010).

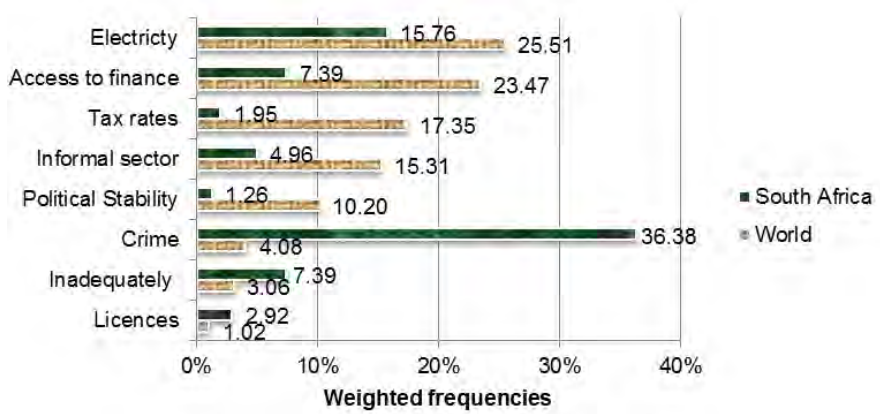

Figure 2: Top constraints reported by enterprises South Africa versus the World

Source: Dihn et al. (2010: 10); World Bank Enterprise Survey of South Africa (2007)

The difference captured by Figure 2 suggests the unsuitability in South Africa of MSME development policies drawn from cross-country studies. In any case, for stakeholders set on promoting MSMEs, it is the top domestic constraints that matter and, better still, the most binding. Before determining the most binding constraint, the next section reviews the Growth Diagnostic framework upon which the study is based.

\section{Analytical framework and data sources}

\section{Analytical framework}

Hausmann et al. (2005) provide a theoretical framework, Growth Diagnostics, to determine a binding constraint. Two arguments are implicit in the framework. The first is that for developing countries to improve their citizens' living standards, economic growth is what is required the most. The second is that economic growth is always contextdependent varying from setting to setting. The framework is based on the observation that in any setting, obstacles to growth will not constrain equally, i.e. some obstacles will have a greater effect than others but one, the binding constraint, will have the largest effect on growth. It is that binding constraint that keeps growth in check. Should the binding constraint be identified and eliminated, a welfareimproving equilibrium emerges in that setting. The challenge is then twofold: identifying the binding constraint, and designing policies to eliminate it.

How then does one "sift through what may seem like a bewildering array of problems to hone in on the most likely culprits for growth failures through a combination of simple theory and suggestive empirics"? (Rodrik, 2010: 35). The framework is not prescriptive. Dihn et al. (2010) and Ayyagari et al. (2008) use different approaches to determine the top constraints: the former use a count of responses complemented by regression analysis, and the latter, DAG methodology. Once sifted, both use regression analysis to determine the top constraint with the largest effect on growth. 
It is indeed expedient to identify the most binding problem in a setting because policies can be specific in design and execution. But there are many reasons to be cautious in ebulliently adopting a framework that singles just one impediment in a bewildering array of many. Three reasons need particular mention. Firstly, the framework's underlying assertion that in any setting only one constraint matters most is very restrictive. It implicitly assumes homogeneity of subjects in that setting and that the effects of the binding constraint will be about the same across all. Secondly, as Ayyagari et al. (2008) find, some effects of obstacles on growth can be indirect such that it is possible that a seemingly minor obstacle is responsible for what the framework diagnoses as binding. In such a situation, it is reasonable to posit that tackling the binding constraint as defined by the framework will not improve growth. Thirdly, it can be impractical for policy to attend to some binding constraint because of limited resources or because the constraint can only be eliminated over time. Crime, corruption, informality of the economy and political instability are examples. In all three reasons for caution, a pragmatic approach is probably to take note of constraints whose effects are most close to that of the binding constraint. The problem is that once the binding constraint is determined no attention appears to be given to what would have been discarded in the sifting process. This paper attempts to retain the framework's holistic analysis of constraints right through to the results by not quickly discarding obstacles in the sifting process. This ensures that the interpretation of the results from the frameworks is not solely focused on the binding impediment but other serious challenges as well.

As background to the analysis, it is important to refer to a study by Rodrik (2008) which sought to understand why unemployment has remained high in South Africa. Reviewing the economy over three decades, Rodrik (2008) finds that unemployment is largely explained by the increasing capital intensity of the manufacturing and mining sector along with a growing financial sector, all of which shored up demand for highly skilled workers while job opportunities for the less skilled waned. Rodrik (2008) shows that it is less likely that jobs will be created by large firms as has been the case in the past. Instead, for job creation, policies must promote new sectors and entrepreneurship. This affirms the need to understand obstacles to the growth of emerging enterprises.

\section{Application of analytical framework}

Many studies have shown that MSME growth is considerably explained by firm age (Haltiwanger, Jarmin \& Miranda, 2013), the sector in which it operates (Soderbom \& Teal, 2003), ownership structure such as ethnic origins and gender of owners (Kantor, 2005; Raturi \& Swamy, 1999) and location (Gelb et al. 2007; Aterido \& HallwardDriemeier, 2010). On the back of this literature, it is fair to expect that the effect of an obstacle on growth will likewise vary across the categories of MSME such as age, sector, ownership, and location in South Africa. Accordingly, the analytical framework groups firms in the said categories.
Categorising firms in this manner is also useful as policy makers often direct support to specific groups.

In this paper, growth is defined as the log difference between the number of full-time employees in the period prior to the survey, 2003, and the time the survey was done in 2007:

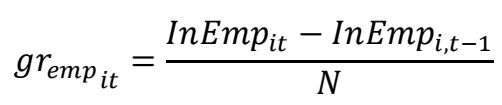

where $g r_{-} e m p_{i t}$ is the growth of firm $i$ at time $t, E m p_{i t}$ is the number of its full-time employees in 2007, $E m p_{i, t-1}$ in 2003 and $N$ is the number of years between the two periods. Alternatively, growth can be similarly based on sales.

The analysis seeks to determine the binding constraints and constraints with notable effects and this is done using two approaches. The first approach is through four sequential stages while the second explores the effects of the obstacles using a model with interaction terms.

\section{The first approach}

The effects of an individual obstacle on growth are first observed using the following model.

Model 1:

$$
\begin{aligned}
g r_{e m p}=\beta_{0}+ & \text { Individual obstacle } \\
& + \text { Firm characteristics } \\
& + \text { Market characteristics }+\varepsilon_{1}
\end{aligned}
$$

Firm characteristics include 2006 sales, the number of fulltime paid employees in 2003, the square of the number of full-time paid employees at the end of 2006, firm age, the square of firm age, a dummy for whether firm is a subsidiary, and a dummy variable for foreign ownership of firm that is above $10 \%$. Market characteristics include a dummy for direct exports above $10 \%$ of sales and a dummy for manufacturing sector. Overall, the control variables are such that the results of this paper are comparable to similar studies.

The analysis proceeds to observe the impact of all obstacles on growth at once in Model 2.

Model 2:

$$
\begin{gathered}
g r_{\text {emp }}=\beta_{0}+\beta_{\text {all } 15 \text { obstacles }}+\beta_{\text {firm characteristics }} \\
+\beta_{\text {market characteristics }}+\varepsilon_{2}
\end{gathered}
$$

In the third stage, the significant obstacles from Model 1 and 2 are used.

\section{Model 3:}

$$
\begin{aligned}
g r_{\text {emp }}=\beta_{0}+\beta_{\text {only significant obstacle in Model } 1 \text { and } 2} & \\
& +\beta_{\text {firm characteristics }} \\
& +\beta_{\text {market characteristics }}+\varepsilon_{3}
\end{aligned}
$$




\section{The second approach}

In the second approach, interactions between some of the groups are allowed and the top constraints are determined by estimating the following regression.

Model 4:

$$
\begin{aligned}
g r_{\text {emp }}=\beta_{0}+\beta_{\text {interaction term }}+\beta_{15 \text { obstacles }} & \\
& +\beta_{\text {firm characteristics }} \\
& +\beta_{\text {market characteristics }}+\varepsilon_{4}
\end{aligned}
$$

where the interaction term is each of the 15 obstacles interacting with the small and with the medium firms in turns. Results from the three earlier stages compel us to drop micro enterprises from the interactions because of the relatively small sample.

A similar analysis is run in parallel, where instead of employment growth, sales growth is used. Those results are not presented but reference to them is made when discussing results of the models above.

\section{Decision criteria}

Results are summarised in Tables 4 to 6. For the key question (i.e. what is the binding constraint for the growth of MSMEs in South Africa?), three possible outcomes are expected from the methodology outlined. One outcome is a binding constraint for each category of firms in Model 3. The binding constraint must have a significant negative effect on growth. An obstacle can be deemed binding in Model 3 subject to the criterion given in B. below. The two other likely outcomes occur in the absence of a binding constraint. One would be when there is evidence that the effect of an obstacle on growth is negative and significant in Model 1 and 2. Such an outcome will be referred to as a constraint with notable effects. Another likely outcome will be when there is insufficient evidence that any of the constraints impacts growth in a meaningful way. On such outcomes no further investigations are done but the possible implications are discussed. In sum then, the analysis and decision-making criteria on what is a binding constraint or a constraint with notable effect is as follows:

The first approach

A. With reference to Model 1 , the outcome is a constraint with notable effects if, in the respective category of enterprises, it is the only constraint with a significant negative impact on growth given that none other(s) emerges significant in Model 2.

B. With reference to Model 2, the outcome is a binding constraint if it is significant and is the only constraint that is significant given that no other constraint was found significant in Model 1. If one or more constraints are significant in Model 2 or, in addition, at least one or more from Model 1, then the binding constraint is determined by proceeding with all such significant constraints from Models 1 and 2 to Model 3.
C. With reference to Model 3, the outcome is a binding constraint if significant. Should more than one emerge significant then the constraint with the largest marginal effect on growth will be deemed the most binding and the other significant ones, constraints with notable effects.

D. There is no reporting on categories of firms where constraints have a less than notable effect on growth.

The second approach

E. With reference to Model 4, the constraint with the most effect is determined by counting the number of times a constraint has a significant negative effect on the interaction terms. The group or category of firms most affected by an obstacle is also determined by a count of obstacles negatively affecting the group significantly. .

\section{Data}

The analysis uses data from two World Bank Enterprise Surveys $^{3}$ conducted in South Africa in 2003 and 2007. Both were conducted in Cape Town, Durban, Johannesburg and Port Elizabeth. In 2007, 1,057 enterprises were surveyed: 120 micro, 375 small, 366 medium and 196 large. All micro enterprises surveyed were in Johannesburg. In 2003, 603 firms were covered of which 191 were also surveyed in 2007 and are included in the 1,057 firms of 2007. It is the matched set of 191 enterprises which the study utilises to track the importance of access to finance over time as it emerges that finance is a relatively less important obstacle. The importance of finance is also tracked by comparing the unmatched sample of 412 enterprises in 2003 to 866 enterprises in 2007. Except when exploring the importance of access to finance over time, the paper uses the 2007 survey data only.

In the Enterprise Surveys, firms rate 15 obstacles on a scale of 0 to 4 where 0 is no obstacle, 1 is minor, 2 moderate, 3 major, and 4 very severe. The obstacles are access to finance, access to land, business licensing and permits, corruption, courts, crime, customs and trade regulations, electricity, inadequately educated workers, labour regulations, political instability, practices of informal sector competitors, tax administration, tax rates, and transportation of goods and supplies.

Since the measures of the 15 constraints are categorical, there are three alternative approaches of handling them in the analysis. One would be to capture the categorical measures as they are, which would make interpretation and comprehension of results convolutedly confusing given the five categories. Another would be to reduce the number of categories to for instance two, where one is 'no obstacle' and the other is 'obstacle'. Interpreting results from the two

\footnotetext{
${ }^{3}$ Enterprise Surveys were launched in 2002 to gather firm-level data in developing economies using a uniform survey instrument and sampling method. A description of the survey instrument and sampling methodology is outlined in Kuntchev, Ramalho, Rodriguez-Meza \& Yang (2012). Many researchers have used the Survey data to compare private sector development issues across countries but few solely focus on one country.
} 
categories would be straightforward but at the loss of information in the ordered categorical ratings. The third alternative is to treat the categories as weak proxies of an otherwise continuous variable and use the resultant mean. The third alternative, which this paper uses, is adopted by Beck et al. (2005) and Dihn et al. (2010).
Descriptive statistics for the obstacles are reported in Table 3. Table 2 reports summary statistics of the 861 MSMEs by age, sector, ownership, and location. Like Dihn et al. (2010), an employment-based measure of growth is used as opposed to the sales-based measure as the latter is more volatile.

Table 2: Employment growth rates by enterprise category

\begin{tabular}{|c|c|c|c|c|c|c|}
\hline Category & & Obs. & Mean & Std. Dev. & Min & Max \\
\hline & All & 883 & 0.0761 & 0.1047 & -0.7068 & 0.5973 \\
\hline & Large firms & 193 & 0.0611 & 0.1053 & -0.7068 & 0.4176 \\
\hline & MSMEs & 690 & 0.0803 & 0.1042 & -0.2310 & 0.5973 \\
\hline \multirow[t]{3}{*}{ Size } & Micro & 68 & 0.0216 & 0.1104 & -0.2310 & 0.4621 \\
\hline & Small & 281 & 0.0936 & 0.1090 & -0.1959 & 0.5973 \\
\hline & Medium & 341 & 0.0811 & 0.0947 & -0.2310 & 0.4851 \\
\hline \multirow[t]{3}{*}{ Age } & Young & 147 & 0.0960 & 0.1076 & -0.2310 & 0.3662 \\
\hline & Mature & 304 & 0.0854 & 0.1093 & -0.2310 & 0.5973 \\
\hline & Old & 239 & 0.0642 & 0.0930 & -0.2310 & 0.4176 \\
\hline \multirow[t]{3}{*}{ Sector } & Retail & 171 & 0.0646 & 0.1053 & -0.2310 & 0.5973 \\
\hline & Services & 156 & 0.0759 & 0.1034 & -0.1865 & 0.5365 \\
\hline & Manufacturing & 361 & 0.0892 & 0.1032 & -0.2310 & 0.4851 \\
\hline \multirow[t]{3}{*}{ Region } & Cape Town & 96 & 0.0712 & 0.1057 & -0.2310 & 0.3662 \\
\hline & Durban-Port Elizabeth & 135 & 0.1107 & 0.0958 & -0.0278 & 0.5365 \\
\hline & Johannesburg & 391 & 0.0823 & 0.1013 & -0.1959 & 0.5973 \\
\hline \multirow[t]{5}{*}{ Ownership } & African & 234 & 0.0858 & 0.1128 & -0.2310 & 0.4851 \\
\hline & Asian \& other & 188 & 0.0808 & 0.1048 & -0.2310 & 0.5973 \\
\hline & European & 268 & 0.0752 & 0.0957 & -0.2310 & 0.5365 \\
\hline & Female & 149 & 0.0756 & 0.1083 & -0.1865 & 0.5365 \\
\hline & Male & 530 & 0.0812 & 0.1034 & -0.2310 & 0.5973 \\
\hline
\end{tabular}

Source: Authors' estimations based on World Bank Enterprise Surveys of South Africa (2007) 
Table 3: Variables descriptions and summary statistics

\begin{tabular}{|c|c|c|c|c|c|c|c|}
\hline Variable & Description & Obs. & & Min 1 & Max & Mean & SD \\
\hline Micro & Number of employees & 120 & & 1 & 4 & 2.2833 & 1.2243 \\
\hline Small & Number of employees & 375 & & 5 & 20 & 10.0930 & 4.4950 \\
\hline Medium & Number of employees & 366 & & 21 & 99 & 41.9290 & 21.6650 \\
\hline Large & Number of employees & 196 & & 100 & $\begin{array}{l}96 \\
00\end{array}$ & 426.4850 & 979.344 \\
\hline Firm age & 2006 minus the year firm begun operating in South Africa & 1056 & & 1 & $\begin{array}{l}14 \\
1\end{array}$ & 15.9290 & 17.7736 \\
\hline Young & Up to 5 years & 325 & & 1 & 5 & 2.8369 & 1.5359 \\
\hline Mature & Between 6 and 15 years & 360 & & 6 & 15 & 9.5278 & 2.8105 \\
\hline Old & Above 15 years & 370 & & 16 & $\begin{array}{l}14 \\
1\end{array}$ & 33.6092 & 19.6763 \\
\hline Experience & $\begin{array}{l}\text { How many years of experience working in this sector does the top manager } \\
\text { have? }\end{array}$ & 1056 & & 1 & 61 & 13.7311 & 10.7040 \\
\hline Gender & Dummy for female ownership & 847 & & 0 & 1 & 0.2361 & 0.4250 \\
\hline $\begin{array}{l}\text { Access to } \\
\text { finance }\end{array}$ & $\begin{array}{l}\text { How much of an obstacle access to and cost of finance is an to the firm's } \\
\text { operations }\end{array}$ & 860 & & 0 & 4 & 0.8826 & 1.2569 \\
\hline Access to land & How much of an obstacle access to land is to the firm's operations & 860 & & 0 & 4 & 0.5884 & 1.0877 \\
\hline Licensing & $\begin{array}{l}\text { How much of an obstacle business licencing/permits are issues to the firm's } \\
\text { operations }\end{array}$ & 860 & & 0 & 4 & 0.4349 & 0.8814 \\
\hline Corruption & How much of an obstacle corruption is to the firm's operations & 860 & & 0 & 4 & 0.9570 & 1.2393 \\
\hline Courts & How much of an obstacle functioning of courts are to the firm's operations & 860 & 0 & 4 & & 0.1953 & 0.5921 \\
\hline Crime & How much of an obstacle crime, theft and disorder is the firm's operations & 860 & 0 & 4 & & 1.9547 & 1.2817 \\
\hline $\begin{array}{l}\text { Customs } \quad \& \\
\text { trade }\end{array}$ & $\begin{array}{l}\text { How much of an obstacle customs and trade regulations are to the firm's } \\
\text { operations }\end{array}$ & 860 & 0 & 4 & & 0.2105 & 0.6281 \\
\hline Electricity & How much of an obstacle electricity is to the firm's operations & 860 & 0 & 4 & & 1.1395 & 1.3273 \\
\hline $\begin{array}{l}\text { Inadequately } \\
\text { educ }\end{array}$ & $\begin{array}{l}\text { How much of an obstacle inadequately educated workers are to the firm's } \\
\text { operations }\end{array}$ & 860 & 0 & 4 & & 0.6349 & 1.0025 \\
\hline $\begin{array}{l}\text { Labour } \\
\text { regulations }\end{array}$ & How much of an obstacle labour regulations are to the firm's operations & 860 & 0 & 4 & & 0.5058 & 0.9098 \\
\hline $\begin{array}{l}\text { Political } \\
\text { instability }\end{array}$ & $\begin{array}{l}\text { How much of an obstacle political instability presents is to the firm's } \\
\text { operations }\end{array}$ & 860 & 0 & 4 & & 0.2733 & 0.7180 \\
\hline Informal sector & $\begin{array}{l}\text { How much of an obstacle are practices of informal competitors to the firm's } \\
\text { operations }\end{array}$ & 859 & 0 & 4 & & 0.8312 & 1.1356 \\
\hline $\begin{array}{l}\text { Tax } \\
\text { administration }\end{array}$ & How much of an obstacle tax administration is to the firm's operations & 860 & 0 & 4 & & 0.2593 & 0.6868 \\
\hline Tax rates & How much of an obstacle tax rates are to the firm's operations & 859 & 0 & 4 & & 0.4144 & 0.8518 \\
\hline Transportation & $\begin{array}{l}\text { How much of an obstacle is transportation of goods and services to the firm's } \\
\text { operations }\end{array}$ & 860 & 0 & 4 & & 0.5163 & 0.9399 \\
\hline sales_06 & Sales in 2006 & 859 & 7,200 & 328,00 & 00,000 & $10,300,000$ & $25,700,000$ \\
\hline emp_03 & Number of employees in 2003 & 694 & 0 & 150 & & 20.9798 & 21.7520 \\
\hline lab_sqd & Square of the number of full-time paid employees at the end of 2006 & 859 & 1 & 14400 & & 1,003 & 1,858 \\
\hline age_sqd & Square of firm age & 859 & 1 & $4,060,2$ & 225 & 5,076 & 138,525 \\
\hline part_of & Dummy for being part of a group of firms & 856 & 0 & 1 & & 0.2570 & 0.4372 \\
\hline own_foreign & Dummy for ownership above 10 percent & 859 & 0 & 1 & & 0.0873 & 0.2825 \\
\hline Export & Dummy for direct exports above 10 percent & 859 & 0 & 1 & & 0.0477 & 0.2133 \\
\hline
\end{tabular}

Source: Authors' estimations based on the World Bank Enterprise Surveys of South Africa (2007)

\section{Empirical results on binding constraints to growth}

Table 4 summarises the results of the first approach, Models 1 to 3 . The marginal effects of the binding constraints are presented in Table 5. These results are discussed next followed by a discussion of the results of Model 4 , the second approach.

\section{The binding constraints: first approach}

Except for small firms of European ownership or in Cape Town, the results show that access to finance does not impact the growth of all other MSMEs significantly. The effects of access to finance on the sales-based growth measure are not significant for all MSMEs. The relative insignificance of access to finance is discussed later in the paper. The analysis does not find a binding constraint in the full sample of firms that includes 196 large enterprises. When the large firms are dropped from the analysis so leaving 861 MSMEs, some significant growth obstacles emerge. Excluding large firms also improves the quality of results with adjusted R-squared improving from an average of 4 percent for all firms on the 15 individual regressions of Model 2 to 78 percent for micro enterprises.

Of the 17 enterprise subgroups studied in the 5 categories of Table 2, it is in the full sample of MSMEs, the medium, young and male-owned firms that the search for a binding constraint progressed to Model 3. For the four categories, 'courts' is the binding constraint. For young firms, the regressions of individual obstacles of Model 1 find only courts significant. However when all constraints enter the regression at once, practices of competitors in the informal sector emerge as the only significant problem. Additionally, the parallel analysis based on sales growth finds tax 
administration significant when all constraints enter the regression at once: it is the only significant outcome from all the sales growth-based regressions. With three constraints for young firms, the analysis proceeds to Model 3, entering only courts and practices of competitors in the informal sector in the regression. Courts emerge as significant. Given that ignoring tax administration which was significant in the sales growth-based regression may justifiably communicate some incompleteness of the analysis, the study explores what emerges when the three constraints are regressed at once on the employment-based growth measure first and then on sales-based growth measure. On the employmentbased growth, only courts is significant. On the sales-based measure, courts and practices of the informal sector are significant but tax administration presents no meaningful effect. With reference to the average marginal effects the binding constraint for young MSMEs is therefore the efficacy of the judicial system i.e. courts.

All else held constant, there is basis from this study to say that the efficacy of the legal system reduces the propensity of young firms to create an additional job by, on average, 2.83 percent in South Africa (see the average marginal effects in Table 5). African-owned firms have the highest growth rates and for them, tax administration is binding reducing the likelihood of an additional job being created by 3.13 percent. MSMEs in the retail sector have 'business licensing and permits' as their most binding constraint. Practices of competitors in the informal sector are the most binding constraint for enterprises owned by those of Asian origin. Enterprises in Johannesburg are affected by electricity supply problems the most. For MSMEs as a whole, 'courts' is binding and transport and electricity are constraints with notable effects. But thus far, the analysis has not found a notable constraint for micro, small, mature, old, European- and female-owned enterprises and firms based in Cape Town, Durban and Port Elizabeth. Interesting results emerge from the second approach, Model 4.

\section{The binding constraints: second approach}

Ideally, interactions would include all five enterprise groups (by size, age, sector, location, gender and ethnic origin) and the subgroups. However, a sample of 861 is too small to be spread across all possible combinations. The analysis designates firm size as the reference category which is then interacted with each of the other categories' subgroups. Micro enterprises are largely homogenous: all are from one locality, 80 percent are African-owned and three-quarters are retailers. Interacting micro enterprises with other groups would yield limited observations and meaning. Micro enterprises are therefore dropped in all interactions. The results of the interaction model are reported in Table 6 .

Table 6 reports the effects of each obstacle when it interacts with small or with medium firms and one of the subgroups (i.e. young, old, services, etc.). Table 6 can be read either horizontally along the rows or vertically along the columns. Overall, across all categories of firms such as Young, Mature, Old, etc., the obstacles tend to have negative effects on small businesses than medium-sized businesses. Of all the obstacles, Crime, Transport, Electricity and Competition in the informal sector, in that order, are the obstacles with the most significant negative effect across the categories of small scale businesses. Other obstacles with significant negative effects include Customs regulation, Workers' education, Corruption and Court. The three obstacles with the least negative effect are Access to land, Access to Finance and Tax administration. For instance, by looking at access to finance across the category of firms, it can be seen that the obstacle is significant in 2 of the 14 interactions (i.e. European-owned and Cape Town-based small firms). Interestingly, the effect of access to finance is negative for all small firms except the African-owned.

Reading the results along the columns, i.e. vertically, the effects of all obstacles on each of the categories of firms can be seen. For example, the first column of Table 6 shows the effects of each obstacle on young small firms where only 'practices of competitors in the informal sector' is significant. For small firms in Durban and Port Elizabeth, all 15 obstacles have no significant effect on growth. One of the many plausible explanations is that the survey instrument may not have picked up key issues affecting growth in those areas. On the other hand, 9 of the 15 obstacles have significant negative effect on the retail, Asian-owned and Johannesburg-based small firms. For Johannesburg-based small firms, the obstacles that have the most significant negative effect (at 1\% level of significance) are Crime, Customs regulations, Electricity, and Competition in informal sector. These were closely followed by Corruption, Workers' education and Transport which were significant at $5 \%$ level of significance. Notably, male-owned small firms are significantly affected by 8 out of the 15 obstacles while only 3 are significant for female-owned small firms despite the fact that many studies have shown that female-owned firms face more obstacles. Further research would help to explain these differences. 
Table 4: Obstacles that constrain MSMEs' growth the most in South Africa

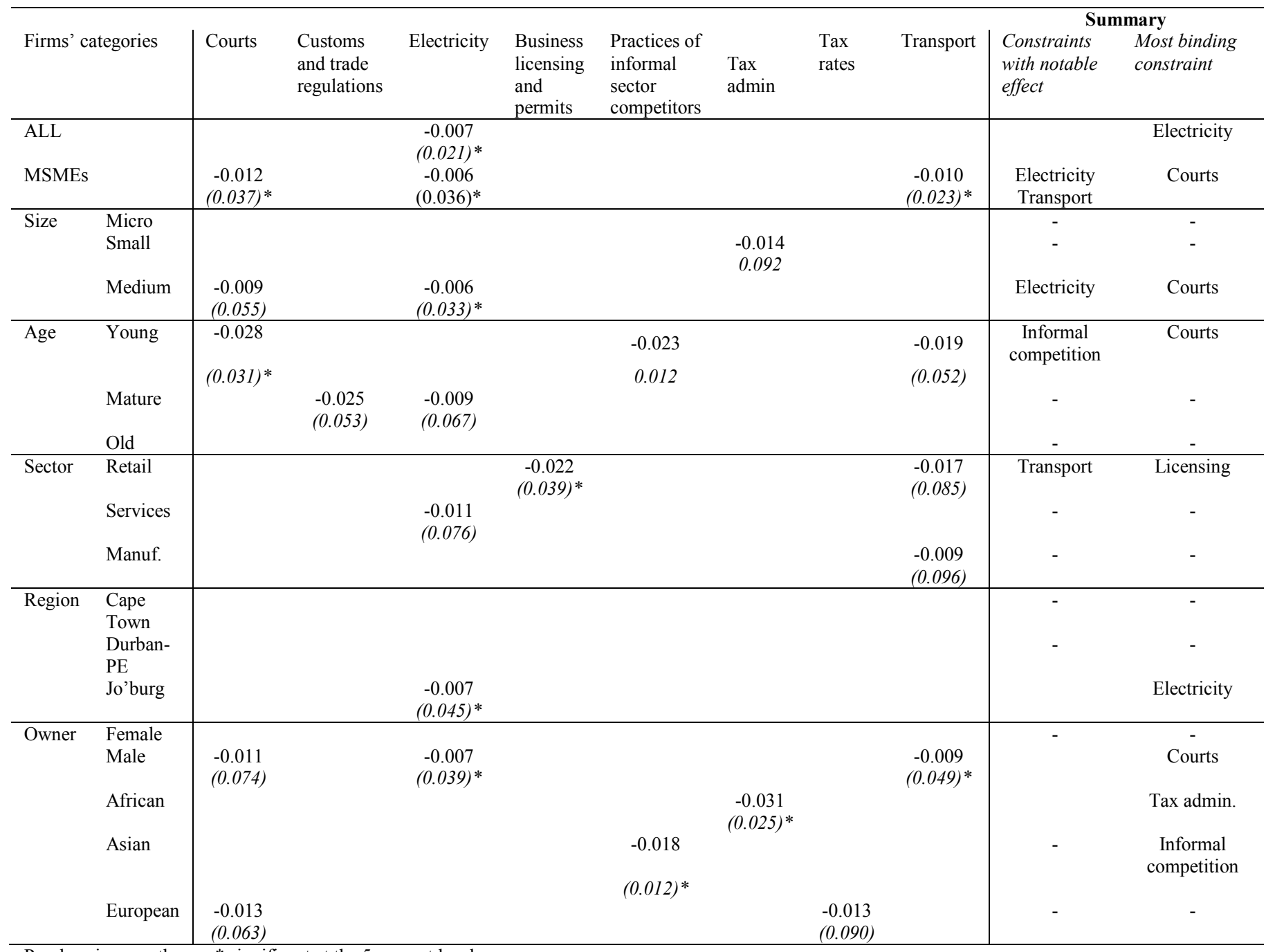

P-values in parentheses; * significant at the 5 percent level

Source: Authors' estimations based on World Bank Enterprise Surveys of South Africa (2007)

Table 5: Marginal effects of the binding constraints

\begin{tabular}{|c|c|c|c|c|c|c|c|}
\hline \multicolumn{8}{|c|}{ Average marginal effects } \\
\hline \multicolumn{8}{|c|}{$\begin{array}{l}\text { Model VCE : OLS } \\
\text { Expression : Linear prediction, predict () } \\
\text { dy/dx w.r.t. : binding constraint }\end{array}$} \\
\hline \multirow[b]{2}{*}{ Enterprise group } & \multirow[b]{2}{*}{ Binding constraint } & \multicolumn{6}{|c|}{ Delta method } \\
\hline & & $\mathrm{dy} / \mathrm{dx}$ & Std. Err. & $\mathrm{z}$ & $\mathrm{P}>|\mathrm{z}|$ & {$[95 \%$ Conf. } & Interval] \\
\hline$\overline{\mathrm{ALL}}$ & Electricity $^{3}$ & -0.0069 & 0.0030 & -2.3100 & 0.0210 & -0.0127 & -0.0010 \\
\hline Johannesburg MSMEs & Electricity $^{3}$ & -0.0074 & 0.0037 & -2.0100 & 0.0440 & -0.0147 & -0.0002 \\
\hline All MSMEs & Courts ${ }^{\delta}$ & -0.0118 & 0.0057 & -2.0900 & 0.0360 & -0.0229 & -0.0008 \\
\hline Medium & Courts $^{\delta}$ & -0.0085 & 0.0044 & -1.9300 & 0.0540 & -0.0172 & 0.0001 \\
\hline Young & Courts ${ }^{\curvearrowright}$ & -0.0283 & 0.0130 & -2.1900 & 0.0290 & -0.0537 & -0.0029 \\
\hline Male-owned & Courts $^{\delta}$ & -0.0114 & 0.0064 & -1.7900 & 0.0730 & -0.0238 & 0.0011 \\
\hline African-owned & Tax administration $^{3}$ & -0.0313 & 0.0138 & -2.2600 & 0.0240 & -0.0585 & -0.0042 \\
\hline Asian-owned & Practices of informal sector competitors ${ }^{3}$ & -0.0183 & 0.0072 & -2.5400 & 0.0110 & -0.0324 & -0.0042 \\
\hline Retail & Business licensing and permits ${ }^{3}$ & -0.0216 & 0.0104 & -2.0800 & 0.0370 & -0.0419 & -0.0013 \\
\hline
\end{tabular}

${ }^{3}$ Marginal effect estimated at Model 3 stage where all obstacles enter the regression at once

- Marginal effect estimated post model 4 where only significant obstacles from Models 2 and 3 enter the regression

Source: Authors' estimations based on World Bank Enterprise Surveys of South Africa (2007) 
Table 6: Interaction for each obstacle

\begin{tabular}{|c|c|c|c|c|c|c|c|c|c|c|c|c|}
\hline & \multicolumn{2}{|c|}{ Young } & \multicolumn{2}{|c|}{ Mature } & \multicolumn{2}{|c|}{ Old } & \multicolumn{2}{|c|}{ Retail } & \multicolumn{2}{|c|}{ Services } & \multicolumn{2}{|c|}{ Manufacturing } \\
\hline & Small & $\begin{array}{r}\text { Mediu } \\
\mathrm{m}\end{array}$ & Small & $\begin{array}{r}\text { Mediu } \\
\mathrm{m}\end{array}$ & Small & $\begin{array}{r}\text { Mediu } \\
\mathrm{m}\end{array}$ & Small & $\begin{array}{r}\text { Mediu } \\
\mathrm{m}\end{array}$ & Small & $\begin{array}{r}\text { Mediu } \\
\mathrm{m}\end{array}$ & Small & $\begin{array}{r}\text { Mediu } \\
\mathrm{m}\end{array}$ \\
\hline \multirow{2}{*}{ Access to finance } & -0.010 & 0.015 & -0.005 & 0.015 & -0.011 & 0.006 & -0.012 & 0.024 & -0.012 & 0.007 & -0.006 & 0.012 \\
\hline & 0.154 & 0.106 & 0.408 & 0.007 & 0.154 & 0.371 & 0.226 & 0.043 & 0.153 & 0.343 & 0.191 & 0.014 \\
\hline \multirow{2}{*}{ Access to land } & -0.011 & 0.011 & -0.002 & 0.018 & 0.007 & 0.010 & -0.011 & 0.012 & -0.023 & 0.007 & 0.008 & 0.018 \\
\hline & 0.177 & 0.378 & 0.792 & 0.003 & 0.430 & 0.132 & 0.315 & 0.207 & $0.039 *$ & 0.330 & 0.242 & 0.002 \\
\hline \multirow{3}{*}{$\begin{array}{l}\text { Licensing \& } \\
\text { permits }\end{array}$} & -0.002 & 0.023 & & & & & -0.031 & 0.015 & & & & \\
\hline & & & -0.005 & 0.015 & -0.009 & 0.003 & & & 0.003 & 0.018 & -0.001 & 0.009 \\
\hline & 0.892 & 0.070 & 0.585 & 0.079 & 0.426 & 0.809 & $0.023^{*}$ & 0.361 & 0.835 & 0.122 & 0.947 & 0.265 \\
\hline \multirow[t]{2}{*}{ Corruption } & -0.007 & 0.018 & -0.003 & 0.010 & -0.017 & 0.002 & -0.012 & 0.011 & -0.019 & 0.002 & -0.002 & 0.010 \\
\hline & 0.266 & 0.037 & 0.530 & 0.034 & $0.012 *$ & 0.631 & 0.066 & 0.087 & $0.015 *$ & 0.730 & 0.661 & 0.024 \\
\hline \multirow[t]{2}{*}{ Courts } & -0.036 & -0.026 & -0.025 & -0.002 & -0.031 & 0.002 & -0.056 & 0.001 & -0.030 & -0.011 & -0.017 & 0.000 \\
\hline & 0.273 & 0.104 & 0.151 & 0.854 & $0.042 *$ & 0.850 & $0.017 *$ & 0.953 & 0.139 & 0.322 & 0.251 & 0.983 \\
\hline \multirow[t]{3}{*}{ Crime } & -0.006 & 0.013 & -0.010 & 0.008 & -0.012 & 0.002 & -0.013 & 0.004 & -0.017 & 0.002 & -0.002 & 0.012 \\
\hline & 0.164 & 0.012 & $0.007 *$ & & $0.008 *$ & & $0.001 * *$ & 0.359 & $0.000 * *$ & & & \\
\hline & & & $*$ & 0.022 & $*$ & 0.632 & $*$ & & $*$ & 0.589 & 0.681 & 0.000 \\
\hline \multirow{4}{*}{$\begin{array}{l}\text { Customs } \\
\text { regulations }\end{array}$} & -0.014 & -0.023 & & & & & -0.019 & 0.025 & & & & \\
\hline & & & -0.041 & 0.007 & -0.030 & 0.013 & & & -0.051 & 0.009 & -0.026 & 0.002 \\
\hline & 0.304 & 0.217 & & & & & 0.277 & 0.099 & & & 0.026 & \\
\hline & & & $0.017 *$ & 0.579 & 0.092 & 0.103 & & & 0.073 & 0.527 & * & 0.773 \\
\hline \multirow[t]{3}{*}{ Electricity } & -0.005 & -0.001 & -0.015 & 0.004 & -0.015 & 0.003 & -0.024 & 0.001 & -0.018 & 0.002 & -0.007 & 0.005 \\
\hline & 0.428 & 0.944 & $0.002 *$ & & & & $0.017 *$ & 0.878 & & & & \\
\hline & & & $*$ & 0.422 & $0.011 *$ & 0.482 & & & $0.001 * *$ & 0.705 & 0.106 & 0.199 \\
\hline \multirow[t]{3}{*}{ Workers' education } & -0.005 & 0.003 & -0.011 & 0.013 & -0.030 & 0.005 & -0.036 & 0.007 & -0.031 & 0.003 & -0.005 & 0.012 \\
\hline & 0.580 & 0.793 & & & $0.004 *$ & & $0.012 *$ & 0.330 & & & & \\
\hline & & & 0.176 & 0.020 & $*$ & 0.385 & & & $0.011 *$ & 0.708 & 0.449 & 0.016 \\
\hline \multirow[t]{2}{*}{ Labour regulations } & -0.009 & 0.006 & -0.005 & 0.017 & -0.016 & 0.010 & -0.024 & 0.003 & -0.015 & 0.008 & 0.001 & 0.017 \\
\hline & 0.458 & 0.692 & 0.441 & 0.003 & 0.065 & 0.148 & $0.014^{*}$ & 0.781 & 0.106 & 0.262 & 0.850 & 0.001 \\
\hline \multirow[t]{2}{*}{ Political instability } & -0.019 & 0.007 & 0.002 & 0.029 & -0.021 & 0.004 & -0.045 & 0.019 & 0.004 & 0.006 & -0.014 & 0.019 \\
\hline & 0.150 & 0.634 & 0.827 & 0.004 & $0.039 *$ & 0.629 & 0.145 & 0.207 & 0.833 & 0.522 & 0.056 & 0.038 \\
\hline \multirow[t]{3}{*}{ Informal sector } & -0.029 & -0.003 & -0.006 & 0.007 & -0.013 & 0.011 & -0.017 & 0.015 & -0.021 & 0.003 & -0.009 & 0.006 \\
\hline & $0.002 *$ & 0.747 & & & & & $0.046^{*}$ & 0.056 & & & & \\
\hline & $*$ & & 0.308 & 0.215 & 0.079 & 0.083 & & & $0.035 *$ & 0.731 & 0.077 & 0.276 \\
\hline \multirow[t]{2}{*}{ Tax administration } & -0.004 & -0.005 & -0.026 & 0.010 & -0.024 & 0.013 & -0.042 & 0.014 & 0.010 & 0.011 & -0.017 & 0.008 \\
\hline & 0.805 & 0.777 & 0.211 & 0.245 & 0.093 & 0.151 & $0.035 *$ & 0.276 & 0.645 & 0.408 & 0.183 & 0.333 \\
\hline \multirow[t]{3}{*}{ Tax rates } & -0.001 & 0.006 & 0.007 & 0.009 & -0.040 & 0.008 & -0.031 & 0.014 & -0.011 & 0.004 & 0.000 & 0.011 \\
\hline & 0.965 & 0.615 & & & $0.002 *$ & & $0.046^{*}$ & 0.220 & & & & \\
\hline & & & 0.529 & 0.206 & $*$ & 0.265 & & & 0.426 & 0.628 & 0.999 & 0.100 \\
\hline \multirow[t]{2}{*}{ Transport } & -0.021 & 0.019 & -0.015 & 0.002 & -0.025 & 0.006 & -0.053 & 0.004 & -0.028 & 0.005 & -0.009 & 0.007 \\
\hline & 0.108 & 0.212 & $0.041 *$ & 0.768 & $0.023 *$ & 0.348 & $0.00^{* * *}$ & 0.688 & $0.020^{*}$ & 0.474 & 0.193 & 0.288 \\
\hline
\end{tabular}

Source: Authors' estimations based on World Bank Enterprise Surveys of South Africa (2007)

\section{What about access to finance?}

Given the prominence of finance in the literature on MSMEs, it is fair to anticipate reservations to a conclusion that finance is not a top problem in South Africa. As Rogerson (2008) reviews, numerous studies argue that finance is the main problem for MSMEs in South Africa. The previous section finds limited evidence to substantiate such arguments. But comparing how the same firm rated access to finance in 2003 to how it rated the obstacle in 2007, a decline in the financing constraint's importance is observed thus possibly explaining the broadly insignificant effects. Figure 3 shows the shift towards 'no obstacle' for the matched panel set of 191 firms.

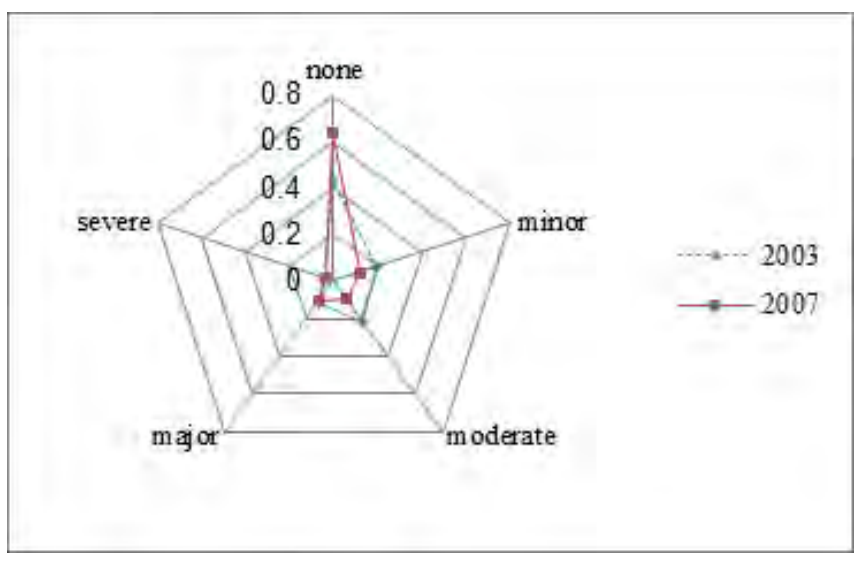

Figure 1: Access to finance 2003 vs. 2007

Source: World Bank Enterprise Surveys of South Africa $(2003 ; 2007)$

An important question arising from Figure 3 is whether the shift is a significant improvement in the perception of 
finance accessibility. Comparing the mean ratings in the radar chart confirms that the improvement is significant with the null hypothesis of equal mean ratings in the two periods not being accepted (see Table 7).

Table 7: Mean-comparison test (paired) for access to finance: 2003 vs. 2007

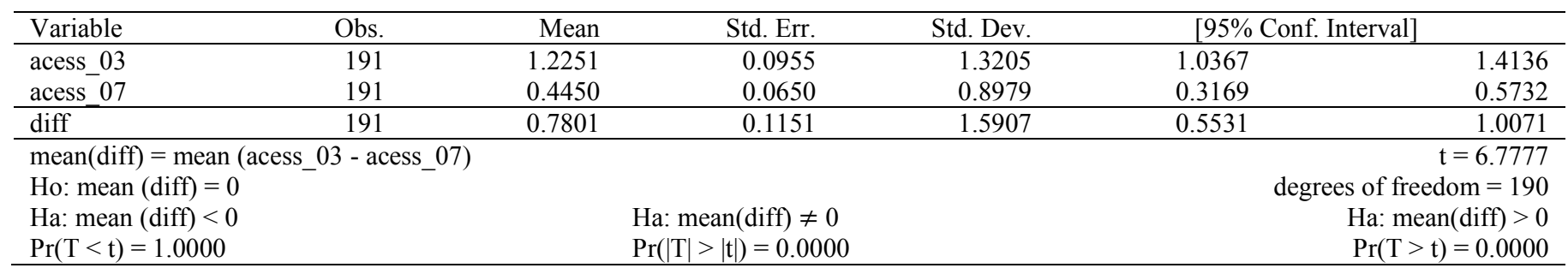

Source: Authors' estimations based on World Bank Enterprise Surveys of South Africa $(2003 ; 2007)$

The 191 firms of course remained in business between 2003 and 2007. But many studies have shown a high failure rate of MSMEs such that the panel set comparison is inherently biased in favour of resilient firms that would have survived obstacles such as access to finance. To offset the bias, a comparison of the mean rating of access to finance of firms surveyed in '2003 only' to those surveyed in '2007 only': 412 firms in 2003 and 866 firms in 2007 is done. Table 8 shows that 2007 ratings are better as the 95 percent confidence interval is well within the 2003 range. The difference is statistically significant at 1 percent.

Table 8: Two-period review of the importance of access to finance importance

Two sample $t$-test with Unequal variances of 2003 vs. 2007

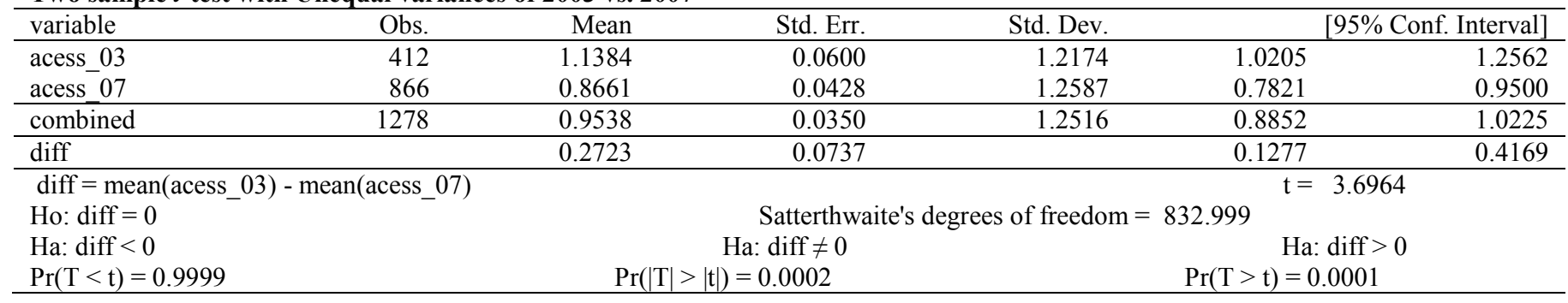

Source: Authors' estimations based on World Bank Enterprise Surveys of South Africa $(2003 ; 2007)$

Firms that report access to finance as a problem would be expected to grow slower than those that say it is not. This comparison is made using both employment and sales growth measures. Table 9 presents the results of the comparison. There is no evidence in this study that firms reporting access to finance as a problem grow at a rate significantly different to those that rate access to finance as not an obstacle. So, this brief detour on the financing constraint in South Africa leads to two important conclusions: firstly that the perception of access and cost of finance improved between 2003 and 2007, and secondly that even though some firms report access to finance to be a problem in 2007, there is no evidence to suggest that their performance is affected by the problem. Although access to finance has been found to be a top constraint and binding constraint for growth of MSMEs elsewhere, MSMEs in South Africa seem to have other more serious problems. The inference from this review of the finance constraint in South Africa is that availability of finance has been improving. 
Table 1: Performance of firms reporting finance as obstacle vs. those not

Panel A: Employment growth

Two-sample t test with unequal variances

\begin{tabular}{|c|c|c|c|c|c|c|}
\hline Group & Obs. & Mean & Std. Err. & Std. Dev. & \multicolumn{2}{|c|}{ [95\% Conf. Interval] } \\
\hline No obstacle & 443 & 0.0763 & 0.0046 & 0.0971 & 0.0672 & 0.0853 \\
\hline Obstacle & 247 & 0.0876 & 0.0072 & 0.1156 & 0.0731 & 0.1021 \\
\hline Combined & 690 & 0.0803 & 0.0040 & 0.1042 & 0.0725 & 0.0881 \\
\hline diff & & -0.0114 & 0.0087 & & -0.0284 & 0.0057 \\
\hline \multicolumn{3}{|c|}{ mean $($ diff $)=$ mean $($ no obstacle - obstacle $)$} & & & & $\mathrm{t}=-1.3102$ \\
\hline \multicolumn{3}{|c|}{ Ho: mean $($ diff $)=0$} & \multicolumn{4}{|c|}{ Satterthwaite's degrees of freedom $=439.987$} \\
\hline \multicolumn{3}{|c|}{ Ha: mean (diff) $<0$} & \multicolumn{2}{|c|}{ Ha: $\operatorname{mean}($ diff $) \neq 0$} & \multicolumn{2}{|c|}{ Ha: $\operatorname{mean}(\operatorname{diff})>0$} \\
\hline \multicolumn{3}{|c|}{$\operatorname{Pr}(T<t)=0.0954$} & \multicolumn{2}{|c|}{$\operatorname{Pr}(|\mathrm{T}|>|\mathrm{t}|)=0.1908$} & \multicolumn{2}{|c|}{$\operatorname{Pr}(T>t)=0.9046$} \\
\hline
\end{tabular}

Panel B: Sales growth

Two-sample t test with unequal variances

\begin{tabular}{|c|c|c|c|c|c|c|}
\hline Group & Obs. & Mean & Std. Err. & Std. Dev. & \multicolumn{2}{|c|}{ [95\% Conf. Interval] } \\
\hline No obstacle & 410 & 0.1127 & 0.0063 & 0.1275 & 0.1003 & 0.1251 \\
\hline Obstacle & 211 & 0.1350 & 0.0110 & 0.1602 & 0.1133 & 0.1568 \\
\hline Combined & 621 & 0.1203 & 0.0056 & 0.1398 & 0.1093 & 0.1313 \\
\hline diff & & -0.0223 & 0.0127 & & -0.0473 & 0.0027 \\
\hline \multicolumn{3}{|c|}{ mean $($ diff $)=$ mean $($ no obstacle - obstacle $)$} & & & & $\mathrm{t}=-1.7581$ \\
\hline \multicolumn{3}{|c|}{ Ho: mean (diff) $=0$} & \multicolumn{4}{|c|}{ Satterthwaite's degrees of freedom $=350.118$} \\
\hline \multicolumn{3}{|c|}{ Ha: mean (diff) $<0$} & \multicolumn{2}{|c|}{ Ha: $\operatorname{mean}(\operatorname{diff}) \neq 0$} & \multicolumn{2}{|c|}{ Ha: mean $($ diff $)>0$} \\
\hline \multicolumn{3}{|c|}{$\operatorname{Pr}(\mathrm{T}<\mathrm{t})=0.0398$} & \multicolumn{2}{|c|}{$\operatorname{Pr}(|\mathrm{T}|>|\mathrm{t}|)=0.0796$} & \multicolumn{2}{|c|}{$\operatorname{Pr}(T>t)=0.9602$} \\
\hline
\end{tabular}

Source: Authors' estimations based on World Bank Enterprise Surveys of South Africa (2007)

\section{Implications for policy and research}

There are some enterprises where the impact of all obstacles on growth was below constraints with notable effects. The affected categories prior to interactions were micro, small, old, female-owned and European-owned, services and manufacturing sector, Cape Town, Durban and Port Elizabeth-based. There are two possible interpretations of this outcome. The first is that the firms have no significant obstacle constraining their growth, meaning that the business environment should be tenable for them. In this interpretation, firms are only exposed to the typical systemic challenges of being in enterprise, namely the ability to innovate and being competitive. The other interpretation is that there are omitted variables and, specifically, that the survey instrument may not have picked up important information from business owners that would have resulted in notable constraints being determined. This interpretation would call for more research to reassess the design of the survey instrument. Jointly, the interpretations bolster arguments for experimental support interventions to MSMEs where interventions that appear to deliver positive impact are scaled-up. In South Africa, such experimentation need not, for instance, emphasise finance in areas where finance is not a constraint.

It is probably important to note that Dihn et al. (2010) find practices of informal competitors and access to finance as the most serious constraints but raise two arguments against the former. The first is by pointing out that the survey instrument lacks objective indicators to validate the constraint and the second is on the reasoning that competition, as the essence of enterprise, cannot be regarded as a constraint. In this light, 'practices of informal competitors' is a rather ambiguous constraint, as indeed is 'courts'. Courts relates to the legal system, its perceived and real efficiency ${ }^{4}$. This is too broad to relate to enterprise growth unless specific aspects of the law are explicitly given for evaluation by firms. Finding courts binding is of limited use to legal reform and design of support measures.

One way of dealing with an ambiguous binding constraint such as courts is to opt for the second most serious on the basis of marginal effects on growth. This would certainly be justifiable in other contexts but for South Africa it is not, because it is plausible to associate courts with crime and crime is the top constraint on count-based methods. Indeed, on a count of significant obstacles in the second approach reported in Table 6 , crime is the most serious obstacle. It is significant in 9 of the 14 interactions. The next important obstacles on the same count basis is practices of informal competitors with 7 , customs and trade regulations and inadequately educated workers with 6 each, corruption with 5 and the rest with 3 and under. So it is fair to conclude that crime is the binding constraint for MSMEs in South Africa and that the significant results of courts affirm this conclusion. It is also important to be cognisant of the possibility that the effects of some obstacles could be indirect. However, the question of how constraints relate and influence each other is beyond this paper but an important issue for further research. It would suffice for this discussion to postulate that a lax legal system increases

\footnotetext{
${ }^{4}$ World Bank Business Environment Surveys (1999-2000) did not have 'courts' on the list but legal obstacles.
} 
crime, limits entrepreneurship and keeps stakeholder such as insurance companies away.

This paper used the 2007 Enterprise Survey data. In preparation for the 2010 FIFA World Cup in South Africa, substantial infrastructure projects to improve the transport system and electricity supply were undertaken nationally. It is likely that the relative importance of some obstacles may have changed because of these projects and other policies since then. A larger follow-up survey would be invaluable as it would show the evolving issues of MSME growth and further enrich debates on the economic impact of such investments and events (Rogerson, 2009).

\section{Conclusion}

The paper identified key constraints to the growth of MSMEs and determined the most binding one. A criterion for identifying top constraints was presented as an alternative to the simple count of responses approach often used in the literature. Using the alternative, crime, electricity and corruption are found to be the top constraints. Firms were grouped by size, age, sector, ethnic and gender ownership and location to determine key constraints for each group. The binding constraint for MSMEs as a whole is crime. Electricity and transportation of goods are constraints with notable effects on growth. Access to finance has limited effects on most MSMEs and a closer review suggests that access has improved over time.

\section{References}

Aterido, R. \& Hallward-Driemeier, M. 2010. 'The impact of investment climate on employment: Does Sub-Saharan Africa mirror other low-income regions?', Policy Research Working Paper 5218. Washington, D.C., USA: The World Bank.

Ayyagari, M., Beck, T. \& Demirguc-Kunt, A. 2003. 'Small and medium enterprises across the globe: A new database', Policy Research Working Paper 3127. Washington, D.C., USA: The World Bank.

Ayyagari, M., Demirguc-Kunt, A. \& Maksimovic, V. 2008. 'How important are financing constraints? The role of finance in the business environment', World Bank Economic Review, 22(3):483516.

Beck, T., Demirguc-Kunt, A. \& Maksimovic, V. 2005. 'Financial and legal constraints to firm growth: Does firm size matter?', Journal of Finance, 60(1):137-77.

Dihn, H.T., Mavridis, S.A. \& Nguyen, H.B. 2010.'The binding constraint on firms' growth in developing countries', Policy Research Working Paper 5485. Washington, D.C., USA: The World Bank.

Gelb, A., Ramachandran, V., Shah, M. \& Turner, G. 2007. 'What matters to African firms? The relevance of perception data', Policy Research Working Paper 4446. Washington, D.C., USA: The World Bank.
Haltiwanger, J., Jarmin, R. \& Miranda, J. 2013. 'Who creates jobs? Small vs. large vs. young', Review of Economics and Statistics, 95(2):347-361.

Hausmann, R., Rodrik, K. \& Velasco, A. 2005. 'Growth diagnostics', Working Paper, JFK School of Government, Harvard University.

Kantor, P. 2005. 'Determinants of women's microenterprise success in Ahmedabad, India: Empowerment and economics', Feminist Economics, 11(3): 63-83.

Kuntchev, V., Ramalho, R., Rodriguez-Meza, J. \& Yang, J. 2012. 'What have we learned from the enterprise surveys regarding access to finance by SMEs?', Policy Research Working Paper. Washington, D.C., USA: The World Bank.

Raturi, M. \& Swamy, A. 1999. 'Explaining ethnic differentials in credit market outcomes in Zimbabwe', Economic Development and Cultural Change, 47(3): 585-604.

Rodrik, D. 2008. 'Understanding South Africa's economic puzzles', Economics of Transition, 16(4): 769-797.

Rodrik, D. 2010. 'Diagnostics before prescription', Journal of Economic Perspectives, 24(3):33-44.

Rogerson, C. 2008. 'Tracking SME development in South Africa: issues of finance, training and regulatory environment', Urban Forum, 19:61-81.

Rogerson, C. 2009. 'Mega-events and small enterprise development: The 2010 FIFA World Cup opportunities and challenges', Development Southern Africa, 26(3): 337-352.

SA National Strategy. 1995. The White Paper on National Strategy for the Development and Promotion of Small Business in South Africa, March 1995, reference WPA/1995.

Soderbom, M. \& Teal, F. 2003. 'Are manufacturing exports the key to economic success in Africa?', Journal of African Economies, 12(1): 1-29.

World Bank Enterprise Survey of South Africa. 2007. Accessed online on 15 June 2013. www.enterprisesurveys.org

World Bank Enterprise Surveys of South Africa. 2003. Accessed online on 15 June 2013. www.enterprisesurveys.org

World Bank, 2013. World Development Report. Washington, D.C., USA: The World Bank. 